\title{
The Arnold Berliner Award 2018
}

\author{
Sven Thatje ${ }^{1}$ (D) \\ Received: 19 February 2018 / Accepted: 28 February 2018 / Published online: 14 March 2018 \\ (C) Springer-Verlag GmbH Germany, part of Springer Nature 2018
}

This year's recipient of the Arnold Berliner Award (Thatje 2013) is Dr. Jan Werner (Johannes Gutenberg-Universität, Mainz, Germany, Fig. 1), in recognition of his research article on the evolution of endothermy in amniotes published in The Science of Nature in 2017 (Werner and Griebeler 2017). Published as a "Concept \& Synthesis" article, this work looks at a fundamental problem in vertebrate evolution: the origins of endothermy.

Endothermy and its evolution in the amniotes, which describe a clade of vertebrates comprising the reptiles, birds, and mammals, remain an unresolved scientific problem. The paper develops a model linking shifts in developmental trajectory to a number of modelling outcomes that are consistent with changes accompanying the origins of birds and mammals, and that are also consistent with many characteristics found in today's endothermic birds and mammals. In particular, the model assumes that an early stop in growth during ontogeny could have played a key role in the evolution of endothermy. This is based on morphological characteristics derived from the fossil record of ancestral amniotes and the assumption that mutations in a number of genes responsible of growth slowed down and stopped growth early in life, meaning the animal's size and appearance resemble that of the juvenile ectothermic ancestor. However, other species characteristics like metabolic rate and life history parameters such as body mass/size at hatching or birth, age and size at which sexual maturity is reached, and the growth rate during early ontogeny are still retained. An early stop in growth during ontogeny may have been instrumental in the development of energy-demanding endothermy, as such process freed energy now available for metabolic heat production and simultaneously shifted up life history parameters in comparison to body size, e.g. larger egg/ offspring size, growth rate. Over evolutionary timescale, these

Sven Thatje

svth@noc.soton.ac.uk

1 Ocean and Earth Science, National Oceanography Centre Southampton, University of Southampton, European Way, Southampton SO14 3ZH, UK characteristics of ancestral endotherms were subject to natural selection and resulted in many adaptations linked to endothermy in today's birds and mammals. The authors make it very clear that this model does not resolve all the issues surrounding the evolution of endothermy. The findings, however, will most likely stimulate new evolutionary, developmental and physiological research on this fascinating scientific problem.

"Concepts \& Synthesis" articles in The Science of Nature present evidence-supported theoretical work that synthesise a research area and provide a perspective on a fundamental

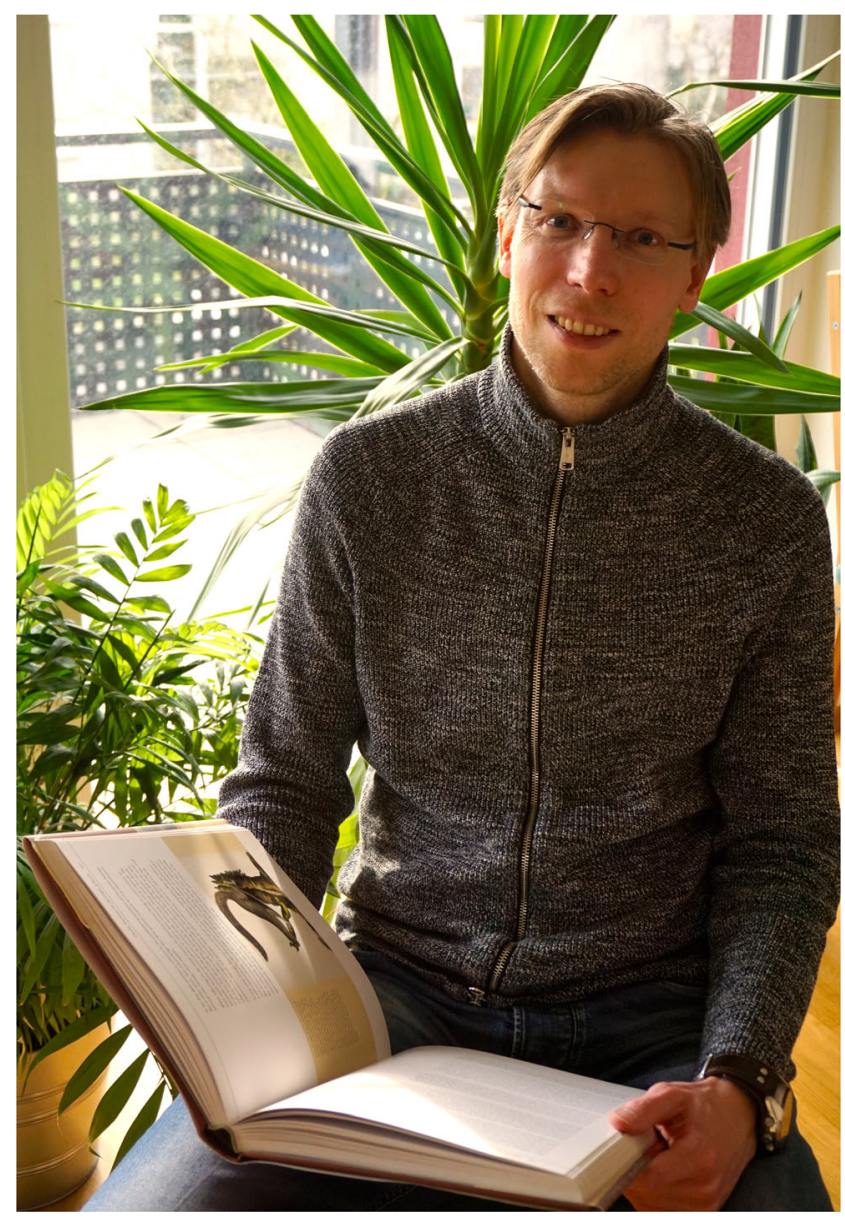

Fig. 1 Dr. Jan Werner, winner of the Arnold Berliner Award 2018 


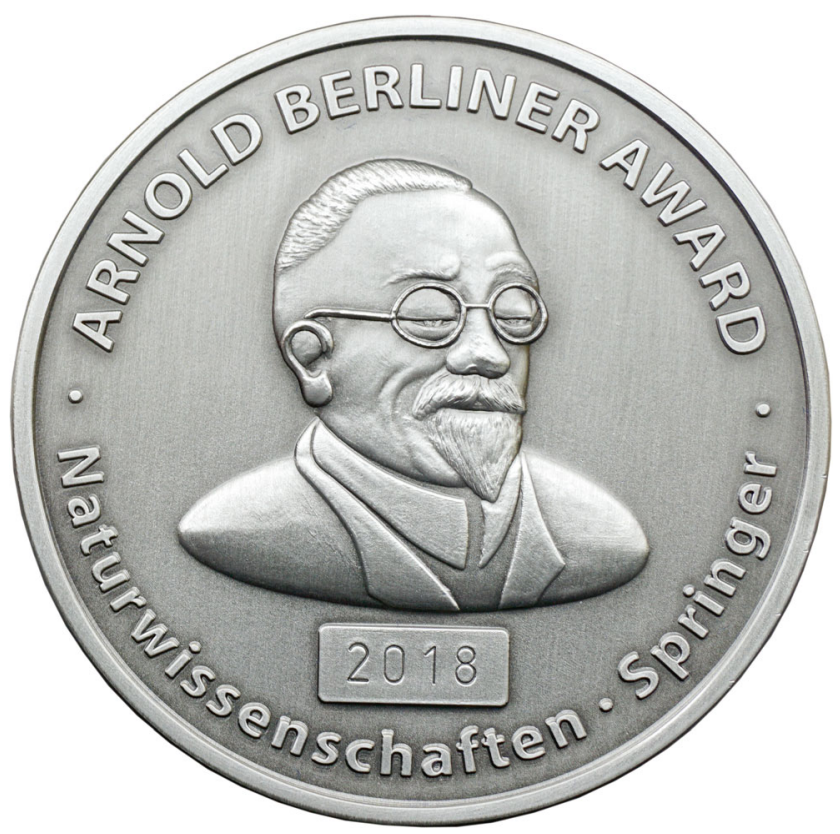

Fig. 2 The Arnold Berliner Award medal. Arnold Berliner (1862-1942) was the founding editor of The Science of Nature and the journal's editor in chief from 1913 to 1935 (Thatje 2012, 2013)

problem. The journal publishes only very few articles of this type, as new theoretical approaches to problem solving are generally scarce. This paper format should not be confused with a traditional Review article and does not therefore aim at a balanced revision of a topic.
The Arnold Berliner Award was established in recognition of the founding editor of Naturwissenschaften (now The Science of Nature, Thatje 2013) who led the journal for the lengthy period of 22 years. The award is sponsored by Springer and is given annually for the best research article published in The Science of Nature during the previous calendar year (Thatje 2012). Criteria are excellence in science, originality and aspects of interdisciplinarity, overall mirroring Arnold Berliner's motivation for initiating the journal. A jury, consisting of select members of the board of editors and the editor in chief, selects the awardee. The award is marked with the Arnold Berliner Award medal (Fig. 2) and is accompanied by a biennial subscription to the electronic edition of The Science of Nature, a 500-euro voucher for Springer ebooks and a cash prize of 250 euros.

\section{References}

Thatje S (2012) Introducing the Arnold Berliner Award. Naturwissenschaften 99(9):675-676

Thatje S (2013) Dr Arnold Berliner (1862-1942); physicist and founding editor of Naturwissenschaften. Naturwissenschaften 100:11051107

Werner J, Griebeler EM (2017) Was endothermy in amniotes induced by an early stop in growth during ontogeny? Sci Nat 104:90. https://doi. org/10.1007/s00114-017-1513-1 